\title{
Inmunobiología de la reproducción
}

\section{Aspectos inmunológicos del factor masculino}

\author{
Dres. Angela P. Cadavid*, William Botero**, \\ Guillermo Henao**, Fabio Sánchez**, Jorge Ossa***
}

\begin{abstract}
RESUMEN. Se presenta una revisión de la literatura acerca de los aspectos inmunológicos del factor masculino haciendo énfasis en las características antigénicas de los componentes del semen, la respuesta de auto y aloanticuerpos que esos componentes pueden estimular y su posible papel en la infertilidad. Se describen las técnicas corrientemente utilizadas para la detección de anticuerpos contra espermatozoides en suero y en secreciones genitales masculinas y femeninas y se mencionan algunas posibilidades terapéuticas para la infertilidad de origen inmunológico.

SUMMARY. This article is a review of the literature on the immunology of the masculine factor, emphasizing the antigenic caracteristics of semen, the auto and allo-antibody responses that those components could stimulate and the role of these antibodies in infertility. The technics currently used for the detection of antisperm antibodies both in serum and genital secretions are described and some therapeutic possibilities for inmunologic infertility are discussed.
\end{abstract}

PALABRAS CLAVES: Infertilidad, espermatozoides, antigenicidad del semen, anticuerpos anti-espermatozoides, espermatogénesis, fecundación.

La reproducción es el evento más importante para la conservación de las especies y también por excelencia el fenómeno más singular del que depende la sobrevivencia del hombre, tanto en forma directa como indirecta, ya que su protección y sustento han dependido siempre de la supervivencia de otras especies. La reproducción humana comprende una serie de etapas: La maduración física y sicológica normal de los futuros padres, el desarrollo normal de óvulos y espermatozoides, la fecundación, la implantación, la placentación, el desarrollo normal del embrión/feto, el parto y la lactancia. En cada una de estas etapas influyen múltiples factores: genéticos, nutricionales, sociológicos, sicológicos, fisiológicos y ginecológicos. Los físiológicos se pueden dividir en endocrinos e inmunológicos.

La reproducción puede alterarse por procesos inmunopatogénicos tales como respuesta inmune contra los espermatozoides, el inadecuado reconocimiento del embrión para asegurar una exitosa placentación y desarrollo del producto, la isoinmunización y la enfermedad de injerto versus huésped. Adicionalmente, la inmunología tiene importancia en otros aspectos de la reproducción: El diagnóstico precoz de la gestación, la posibilidad de vacunas anticonceptivas, la inmunoselección de espermatozoides (de gran trascendencia

* MD, Magister en Inmunología, Investigadora.

** Profesores Depto. Obstetricia y Ginecología, Facultad Medicina U. de A.

*** Profesor Depto. Microbiología y Parasitología, Facultad de Medicina U. de A en la reproducción animal), y la posibilidad de inmunoterapias para restaurar y aumentar la fertilidad.

En los párrafos siguientes se hace una introducción a la inmunobiología de la reproducción, con énfasis en la inmunología del semen y las alteraciones del factor masculino. En otro artículo se presentará una revisión de los aspectos inmunológicos de la interacción madre-feto.

\section{Espermatogénesis}

Hacia la sexta semana de desarrollo embrionario, las células germinales primordiales se transforman en espermatogonias. Cuando el varón llega a la pubertad dichas células inician la mitosis, se especializan y se transforman en espermatocitos primarios. Estos sufren la primera meiosis y dan origen a los espermatocitos secundarios, cada uno de los cuales se divide en dos espermátides que entran en un período de maduración denominado espermiogénesis; durante este proceso la célula pierde gran parte del citoplasma y de la membrana celular. El complejo de Golgi da origen al acrosoma que junto con el núcleo forman la cabeza del espermatozoide; las mitocondrias y centríolos se disponen en uno de los polos para formar el cuello y cerca de éste crece un flagelo que constituye la cola del espermatozoide. Todos estos cambios se inician en el interior de los túbulos seminíferos y terminan a nivel de los conductos excretores del aparato genital, especialmente en el epidídimo. Este proceso de maduración está mediado por la acción de sustancias propias del testículo y de hormonas hipofisiarias y gonadales (1). 


\section{Fecundación}

Un prerrequisito para la penetración de la zona pelúcida por el espermatozoide es la interacción de éste con el recubrimiento glicoproteico del oocito a través de componentes complementarios sobre la superficie de los gametos. Dicha interacción específica, aparentemente, está mediada por la asociación de cadenas de oligosacáridos con sitios de unión sobre la superficie de los gametos los cuales reconocen específicamente dichos carbohidratos. Sobre la membrana del espermatozoide se han encontrado oligosacáridos de tipo $\mathrm{N}$-glicosídico que podrían ser muy importantes en la reproducción ya que contienen grupos de carbohidratos involucrados en la reacción de capacitación, en la interacción del espermatozoide y el huevo y en la fertilización del mismo. Además se han detectado receptores específicos para glicoproteínas que contienen oligosacáridos del tipo $\mathrm{N}$. El hecho de que el ligando y el receptor se encuentren en las mismas zonas de la membrana del espermatozoide, sugiere que el reconocimiento espermatozoide-óvulo es de doble interacción, similar al modelo general del reconocimiento célulacélula (2).

Si se acepta la hipótesis de que el mecanismo de reconocimiento está dado por interacciones duales con unión doble de receptores (2), los espermatozoides podrían reconocerse entre sí y aglutinarse, pero en condiciones normales no lo hacen posiblemente por algunos mecanismos como bloqueo de receptores y/o de aceptores, razones topológicas o leves diferencias en la especificidad de receptores y/o de aceptores (2).

Los espermatozoides pueden ser aglutinados por bacterias, virus, micoplasmas y distintos agentes físicos o químicos; pueden adherirse a células epiteliales y formar conglomerados. Pero también lo hacen por la presencia de anticuerpos aglutinantes en plasma seminal o suero (2).

\section{Inmunología del semen}

Los espermatozoides expresan antígenos de diferenciación únicos que pueden estimular respuestas autoinmunes en el hòmbre y aloinmunes en la mujer. La respuesta inmune antiesperma ocurre como resultado de una ruptura o imbalance en los mecanismos protectores normales que incluyen: a) La barrera testículo-sangre; b) Factores inmunosupresores en el plasma seminal, y c) Mecanismos inmunorreguladores activos en el hombre y la mujer (3). La barrera física del testículo provee un ambiente intratubular secuestrado en el cual las células germinales pueden sufrir meiosis y desarrollarse hasta la maduración. Esta barrera está constituida por la capa de células de Sertoli, que rodean los túbulos seminíferos y forman una unión estrecha entre ellas, excluyendo el paso de linfocitos y proteínas de alto peso molecular así como de inmunoglobulinas y de complemento. Estas células constituyen también una barrera inmunológica porque fagocitan y degradan activamente espermatozoides y productos residuales que serían una fuente de estimulación antigénica si salieran de los túbulos seminíferos. Además las células de Sertoli secretan proteínas específicas que incluyen factores inmunosupresores. Se ha encontrado que algunas de estas proteínas inhiben la blastogénesis de linfocitos y la lisis mediada por complemento. La barrera testículo-sangre puede romperse por trauma físico, químico, infección o vasectomía. Los espermatozoides que se producen después de la vasectomía se degradan en el tracto reproductor y ocurre liberación de productos a través de la rete testis distendida, el epidídimo y el conducto deferente; en estas estructuras no existen células de Sertoli, lo cual hace posible la aparición de una respuesta inmune antiespermatozoide (3).

El tracto reproductor femenino no está "secuestrado" por ninguna barrera física. Sin embargo, los espermatozoides, que son inmunológicamente extraños a la mujer, no suelen desencadenar respuesta inmune. Existen evidencias de que enzimas del plasma seminal afectan la expresión de antígenos de superficie del esperma y de que factores inmunosupresores del plasma seminal pueden disminuir la respuesta antiesperma in vivo (3).

El plasma seminal es una mezcla de secreciones originadas en varias glándulas del tracto reproductor masculino, tales como el epidídimo, las vesículas seminales, la próstata y las glándulas bulbouretrales; además tiene una pequeña cantidad de material transudado de la sangre. Varios componentes de este plasma facilitan el proceso de fertilización: enzimas que ayudan en la eyaculación y en la espermiomigración transcervical; las fosfolipasas, que pueden ser importantes en los cambios de membrana de los espermatozoides durante la capacitación; la fructosa, que es una fuente de energía; los componentes que contienen zinc, que pueden estabilizar sus proteínas nucleares. Además el plasma seminal contiene factores inmunosupresores que protegen los espermatozoides del daño inmunológico y previenen la sensibilización de la hembra. Estos factores pueden interferir directa o indirectamente con las funciones de gran parte del sistema inmune: Inhiben la capacidad de linfocitos $\mathrm{T}$ y $\mathrm{B}$ para proliferar en respuesta a mitógenos y antígenos; disminuyen la fagocitosis por macrófagos y polimorfonucleares, la capacidad de las células NK y linfocitos T citotóxicos para reconocer y destruir tumores o blancos infectados con virus; además inhiben la acción del complemento. Son muchos los factores que se han considerado como inmunosupresores; entre ellos puede mencionarse una molécula como la proteína A-asociada con el embarazo, proteínas de unión al receptor $\mathrm{Fc}$, úteroglobulina, transglutaminasa, complejos proteína-zinc, nucleasas y proteasas seminales, prostaglandina- $E_{2}$ y poliaminas como la espermina y la espermidina (4).

\section{Antígenos del espermatozoide humano}

Los antígenos del espermatozoide humano pueden ser detectados en las diferentes regiones como el acrosoma, el postacrosoma, la región ecuatorial, el segmento intermedio, la cola y la punta de la cola. Han sido identificados varios antígenos específicos: $\mathrm{LDH}^{-\mathrm{C}_{4}}$, la acrosina, la hialuronida$\mathrm{sa}$, los antígenos del grupo $\mathrm{ABO}$, el controvertido $\mathrm{H}-\mathrm{Y}$ y otros.

Los antígenos HLA no se expresan significativamente en el espermatozoide. Los antígenos de grupo sanguíneo $\mathrm{ABO}$ que se encuentran en el plasma seminal de individuos secretores, no parecen ser un factor importante de sensibilización (3).

Los anticuerpos monoclonales son una herramienta de mucha utilidad para el estudio de moléculas estructurales de la membrana y del citoplasma de la célula espermática y sus aspectos de desarrollo y función. Estos anticuerpos permiten el estudio de los cambios de marcadores de super- 
ficie de los espermatozoides durante el proceso de maduración en el tracto genital masculino y sus funciones en el tracto femenino y han permitido involucrar moléculas específicas en el proceso reproductivo (capacitación, reacción del acrosoma, fertilización y desarrollo temprano del embrión). Son útiles también para la purificación de antígenos por inmunoafinidad, para el estudio de la estructura molecular y la actividad biológica de los diferentes epitopes y para determinar la especificidad de especie de los diferentes determinantes antigénicos. Además se están utilizando en el desarrollo de vacunas antiesperma (5).

\section{Causas de infertilidad}

En el hombre los defectos en la calidad del semen son la causa más importante de infertilidad. En la mujer se podrían mencionar: problemas de ovulación, obstrucción de Trompas de Falopio, patología uterina, infecciones, endometriosis y alteraciones del moco cervical. Una causa compartida por ambos sexos es la presencia de anticuerpos contra los espermatozoides; sin embargo la sola presencia de anticuerpos antiesperma puede no dar cuenta definitiva de la infertilidad, sino más bien estar relacionada con lesiones o cambios inmunopatológicos en el tracto genital que serían las directamente responsables (6).

Los anticuerpos pueden estar dirigidos contra los antígenos intrínsecos del espermatozoide, que son producidos durante la maduración de las células germinales, y/o contra los antígenos que los recubren, que se adicionan durante el paso de los espermatozoides por el epidídimo y cuando se exponen al plasma seminal en el eyaculado. Estos anticuerpos pueden tener diferentes efectos, tales como: a) Inmovilizar y/o aglutinar los espermatozoides en el semen o en el tracto reproductor femenino; b) Interferir con el proceso de fertilización por unirse a antígenos de membrana involucrados en la interacción oocito-esperma; c) Afectar diferentes estados del proceso de fertilización como reacción de acrosoma, reconocimiento y penetración de la zona pelúcida; d) Provocar pérdida del embrión pre o post implantación $(3,7)$.

Los anticuerpos contra el esperma pueden encontrarse en suero y/o en secreciones genitales (semen y moco cervical), y pueden ser producidos in situ o ser exudados del suero. Ha habido mucha controversia con respecto a esto, pero la hipótesis más aceptada es que la IgG es de origen sanguíneo y la IgA se produce a nivel local (3). La submucosa del tracto genital masculino es rica en linfocitos, macrófagos y tejido linfático que cuando son retados con material antigénico, reaccionan con producción de anticuerpos. Generalmente se han encontrado títulos más altos en suero que en plasma seminal, pero algunas veces estos anticuerpos pueden estar unidos a los espermatozoides en el semen y no encontrarse suficiente cantidad en forma libre para ser detectados. Con la técnica de unión a inmunoesferas (esferas de poliacrilamida con anti-IgG, anti-IgA o anti-IgM humanas), se han podido hallar estos anticuerpos unidos a los espermatozoides y también identificar la clase de inmunoglobulina (8). La IgA en la cola del espermatozoide está asociada con la pobre penetración de éste en el moco cervical y al parecer esta IgA es la responsable de la aglutinación de los espermatozoides. Los anticuerpos IgG están aparentemente comprometidos con la reducción de la fusión esperma-oocito en el hamster. Los anticuerpos citotóxicos pueden actuar redu- ciendo la supervivencia y/o la motilidad de los espermatozoides y los anticuerpos IgG e IgA pueden actuar sinergísticamente e inhibir la fertilización al reducir la unión del esperma a la zona pelúcida $(8,9)$.

El tracto genital femenino parece producir una respuesta inmune local muy activa y algunas veces se encuentran anticuerpos en moco cervical y no en suero, aunque generalmente se encuentran en ambos. Las Igs G, M, A están presentes en el moco cervical en todas las fases del ciclo menstrual; la concentración más alta corresponde a IgG. Hay evidencias de que ocurre trasudación del suero a la secreción cervical, así como de un componente local del tipo IgA secretoria producida por plasmocitos en la submucosa cervical y de que esta IgA influye en la pobre penetración del moco por el espermatozoide (10).

El esperma es altamente inmunogénico cuando es dspositado en el recto y se promueve la formación de complejos inmunes circulantes (CICs), porque el semen en el recto es fácilmente accesible al sistema inmune y se forman anticuerpos que pasan al tracto reproductor y a todas las mucosas a través del sistema inmune secretorio. Los CICs que se depositan en las células que rodean el tracto genital producen además injuria de tejidos e inflamación por activación del complemento; este daño facilita el contacto de los espermatozoides con el sistema inmune y hace que persista la producción de dichos anticuerpos. La persistencia de CICs en el tracto genital puede incrementar la susceptibilidad a la infección en este sitio, lo que a su vez contribuye a disminuir la fertilidad. Hay evidencias de que los espermatozoides y algunas bacterias comparten determinantes antigénicos por lo cual los anticuerpos que se formen contra los microorganismos pueden reaccionar cruzadamente con los espermatozoides (11). La infección por Chlamydia tracomatis es una causa importante de infertilidad, porque puede unirse a la superficie de los espermatozoides y así aumentar su antigenicidad; puede servir para el transporte de la infección a otros lugares del tracto genital produciendo endometritis, salpingitis y/o cervicitis; además puede desencadenarse una respuesta autoinmune local (humoral y celular) dirigida contra la clamidia y los antígenos de membrana del huésped (12).

Por los métodos clásicos de prueba de aglutinación en gelatina ("GAT") y prueba de aglutinación en tubo y placa ("TSAT") se ha encontrado que la incidencia de anticuerpos antiesperma en hombres de parejas infértiles es de 9-10\% y en cambio es cerca de $1 \%$ en la población normal. En las mujeres de parejas infértiles es de $15-18 \%$ contra un $2 \%$ en las fértiles. Algunas veces puede encontrarse que en una muestra hay reacción positiva por una técnica y negativa por otra, lo cual puede explicarse porque la "TSAT" detecta más anticuerpos contra la cabeza y la "GAT" detecta principalmente anticuerpos contra la cola (6).

Para la detección de anticuerpos contra el semen se han utilizado varios métodos clásicos de aglutinación (en gelatina, en tubos y portaobjetos, en tubos capilares, en placa) y de inmovilización (de Isojima). En la actualidad se han utilizado otras técnicas con metodología más moderna que incluye la reacción de mezclas de inmunoglobulinas que utiliza el mismo principio de la prueba de Coombs, el radioinmunoanálisis (RIA) y la inmunoabsorción enzimática (ELISA) utilizando espermatozoides fijados con glutaral- 
dehído o preparando un extracto de los mismos; el "inmunoblotting", el método de inmunoesferas con anti-inmunoglobulinas pegadas que sirve para detectar los espermatozoides que tengan en su superficie anticuerpos unidos. Otra de las técnicas que se ha utilizado es la inhibición de la función del esperma medida por.inhibición de la fusión con óvulos de "hamster" libres de zona pelúcida $(13,14)$.

También se han encontrado en algunas mujeres anticuerpos contra el óvulo dirigidos principalmente a antígenos de la zona pelúcida. Todavía hay mucha controversia del papel de estos anticuerpos en la infertilidad, debido a que también pueden estar presentes en mujeres fértiles (6).

\section{Terapia de la infertilidad inmunológica}

Se han ensayado varias terapias para el tratamiento de la infertilidad de origen inmunológico, las cuales están encaminadas principalmente a la disminución de los anticuerpos contra los espermatozoides; algunas pueden aplicarse a los dos sexos y otras a uno solo:

a. Uso de condón. El principio en que se basa es el de impedir el contacto de la mujer con la fuente de antígeno (semen) y de esta forma disminuir el estímulo antigénico y la memoria inmunológica frente a él, lo que permite que los títulos de anticuerpos disminuyan. El tiempo para que esto ocurra es variable y puede ser alrededor de 1 año, por lo cual se recomienda hacer seguimientos periódicos de los títulos de anticuerpos hasta que desparezcan (15).

b. Lavado de los espermatozoides e inseminación. Se pretende separar los anticuerpos presentes en el semen, antes de la inseminación, por medio de técnicas de lavado. Este método no ha sido muy exitoso porque es difícil remover los anticuerpos sin dañar los espermatozoides, máxime si aquellos están unidos a éstos. Algunos autores han utilizado la absorción a inmunoesferas de los espermatozoides que tienen anticuerpos unidos, para hacer la inseminación con los espermatozoides libres (15).

c. Inmunosupresión con corticosteroides sistémicos. Se han utilizado varios esquemas que incluyen dosis bajas continuas o dosis altas en forma intermitentr. Los resultados han sido buenos tanto en hombres como en mujeres para disminuir los niveles de anticuerpos específicos, principalmente de IgG, en suero y en secreciones genitales (15).

d. Corticosteroides tópicos. Han sido de utilidad en pacientes con anticuerpos en moco y no en suero. El principio en que se basa esta terapia es el de interferir con la síntesis de anticuerpos a nivel cervical, pero no es por un efecto inmunosupresor sino por un efecto anti-inflamatorio que disminuye la permeabilidad capilar y la migración de leucocitos y lleva a una menor estimulación del sistema inmunológico por los antígenos del esperma (16).

e. Inmunización oral con antígenos del esperma. En modelos animales se está implementando esta terapia con buenos resultados para hiposensibilizar a los machos que tengan anticuerpos positivos para lo cual se administran extractos antigénicos de esperma por vía oral, haciendo uso del concepto de tolerancia oral (17).

\section{BIBLIOGRAFIA}

1. RAMIREZ, J.L. Formación y desarrollo del huevo. En: Botero J., Jubiz A., Henao G., eds. Obstetricia y Ginecología. 3a. ed. Cali: Carvajal, 1985: 54-58

2. CEREZO, A.S.; FERNANDEZ, E.; MAESTRE, A. y col. Receptores de la membrana de espermatozoides humanos aglutinantes. Act Bioquim Clin Latinoameric 1989; 23(1): 53-61.

3. ALEXANDER, N.J.; ANDERSON, D.J. Inmunology of semen. Fertil Steril 1987; 47(2): 192-205.

4. JAMES, K.; HARGREAVE, T. Immunosuppression by seminal plasma and its possible clinical significance. Immunol Today 1984; 5(12): 357-363.

5. MENGE, A.C. Monoclonal antisperm antibodies. Eos Riv Immunol Immunofarmacol 1986; 6(2): 83-85

6. SHULMAN, S. State of the art in immunological aspects of infertility. Eos Riv Immunol Immunofarmacol 1986; 6(2): 59-63.

7. CLARKE, G. Sperm antibodies and human fertilization. Am J Reprod Immunol Microbiol 1988; 17: 65-71.

8. ALEXANDER, N.J. Natural and induced immunological infertility. Curr Opinion Immunol 1989; 1: 1125-1130.

9. RADICIONI, A. Immunoglobulins in seminal plasma. Eos Riv Immunol Immunofarmacol 1986; 6(2): 71-74.
10. CERASARO, M. Immunoglobulins in cervical mucus. Eos Riv Immunol Immunofarmacol 1986; 6(2): 75-77.

11. WITKIN, S.S. Circulating immune complexes and immunological infertility. Eos Riv Immunol Immunofarmacol 1986; 6(2): 86-88

12. DE PlACIDO, G.; PEluSO, G.; COLACURCI, F. et al. Is Chlamydia tracomatis an important cause of immunological infertility? Eos Riv Immunol Immunofarmacol 1986: 6(2): 92-94.

13. DONDERO, F. The classic techniques for sperm antibody detection. Eos Riv Immunol Immunofarmacol 1986; 6(2): 64-66.

14. LENZI, A. The new test for sperm antibody detection. Eos Riv Immunol Immunofarmacol 1986; 6(2): 67-70.

15. SHULMAN, S. Therapy of immunological infertility. Eos Riv Immunol Immunofarmacol 1986; 6(2): 95-96.

16. SCARSELLI, G.F.; CHELO, E.; LIVI, C. et al. Local therapy in female immunological infertility. Eos Riv Immunol Immunofarmacol 1986; 6(2): 98-100.

17. CONGLETON, L. Oral immunization with sperm antigens: Possible therapy for sperm antibodies. Fertil Steril 1989; 52(1): 106-112. 